\title{
History of HTA: Introduction
}

\author{
David Banta \\ University of Maastricht
}

Egon Jonsson

University of Alberta and University of Calgary and Institute of Economics

\section{HISTORY OF HTA: INTRODUCTION}

For the past several years, we have discussed the idea of producing a publication on the history of health technology assessment (HTA). It seemed important to us to develop this history now, while those who lived it can give their own accounts. An exception is Seymour Perry, the first president of ISTAHC and the Director of the first national public program in HTA, the U.S. National Center for Health Care Technology (NCHCT). See the In Memoriam in this issue.

When we finally took action and approached the international community of researchers in HTA, we were overwhelmed by the positive response. We turned to many of the people we knew to be part of the history of HTA, albeit far from everyone due to practical limitations. The great majority of these people present their views of HTA's history in the following studies. More than eighty authors have contributed with forty-four essays on the subject.

With this series of studies, we intend to introduce the history of HTA. To date, no broad-based effort has been made to trace the international history of HTA, now spanning more than three decades. However, some historical documentation has been published on the early development of HTA in different countries (8), the International Society of Technology Assessment in Health Care (ISTAHC) $(2 ; 14 ; 19 ; 20)$, and the International Network of Agencies for Health Technology Assessment (INAHTA) (7).

Inevitably, the essays presented here reflect our own and all other authors' own experiences, biases, and perspectives. We encourage commentaries from those who have been involved in HTA for many years, and have their own perspectives on HTA and its history, to supplement our necessarily imperfect and limited story. These would be welcomed contributions to the special section of the Journal on Commentaries, Views, and Developments in HTA.

Although this compilation of studies on the history of HTA is impressive, we would like to point out that it is far from the whole picture. Several omissions are obvious.
First, this set of studies focuses on developments within the public sector, largely the ministries of health and HTA agencies, and occasionally the public health insurance programs in selected countries. One might argue that a parallel activity in the public sector involves those agencies that register pharmaceuticals. They perform assessments and make critical decisions on an important class of technology. Likewise, funding agencies, the universities, and industry play a key role in HTA as perhaps the largest funding sources for HTAs and as sponsors and organizers for many HTAs. A much longer publication would be needed to explore these dimensions and actors involved in HTA. In addition, the roles of international organizations would need to be further illuminated, such as the many aid agencies, the World Bank, and the European Commission (EC), a strong supporter of the HTA concept in both Europe and some developing countries.

Second, a tragedy of today's world is that the poorest countries, which often have the greatest need for critical assessment to make appropriate and affordable investments in health technology, have a limited basis for making those choices. We are conscious that the many countries of Africa receive little mention in these studies. To our knowledge, no country on that huge continent has an active HTA program, although the African office of the World Health Organization (WHO) has shown interest in the field from time to time. South Africa has some experts in HTA and may move to develop an HTA program. However, it should be noted that evaluative work related to HTA has been carried out in developing countries under the auspices of organizations outside of those countries, for example, by aid agencies, universities, industry, the European Union (EU), and WHO.

Likewise, some countries in Eastern Europe and Latin America, and many countries in Southeast Asia are not yet part of the story. This is unfortunately the case, although some countries show a strong and growing interest in the field, and there are scattered experts and emerging interests in, for example, Turkey, Iran, India, Pakistan, Laos, and Vietnam. Russia has substantial expertise in HTA and evidence-based 
medicine (EBM), but no national government interest can yet be discerned.

\section{THE BEGINNINGS OF HTA}

The field of HTA was developed in a systematic way beginning in the U.S. Office of Technology Assessment (OTA), which published its first report on the subject in 1976 (15). HTA began to spread to the rest of the world in the late 1980s, with the formation of the Swedish Council on Technology Assessment in Health Care (SBU). During the two decades since that time, HTA has spread to nearly all European countries, then to some of the wealthier countries in Central Europe, Latin America, and Asia. This spread has been facilitated with help from international organizations such as the World Bank and, to a lesser extent, the WHO. Also of importance here are the membership associations in HTA, notably ISTAHC and its successor organization, Health Technology Assessment International (HTAi), and the INAHTA. Communication of the principles and outcomes of HTA has been essential in spreading the word about HTA, and here the International Journal of Technology Assessment in Health Care has played a particularly crucial role.

The early products from OTA shaped the field of HTA. The OTA had the opportunity of examining possibilities for the new field, focusing on methods and concentrating on efficacy, safety, and cost-effectiveness (16-18). The key method for HTA involved synthesizing available information, which has generally come to be called "systematic review" by the Cochrane Collaboration and others. In addition, these initial reports examined health policies that might be influenced by HTA, or that might use HTA results in their decisions. These two critical issues largely determined the general shape of HTA programs around the globe.

An early result of these reports on efficacy and safety was that they encouraged the U.S. Congress to develop the National Center for Health Care Technology (NCHCT), which existed from 1980 to 1982 . This was the first national agency in the world to deal with HTA (formally speaking, OTA existed to serve the U.S. Congress, not the general public or the Executive Branch of the U.S. government). In several ways NCHCT was a pioneer during its short life, especially in advising the U.S. Medicare program on technologies to cover. Other pioneering actions of NCHCT were to carry out systematic reviews on selected technologies, to develop methods for setting priorities between health technologies, and to begin to identify new and emerging health technologies as candidates for assessment.

After NCHCT was abolished, the Institute of Medicine (IOM) of the National Academy of Sciences decided to develop a national Council on Health Care Technology to serve in its stead. The Council performed several important tasks. However, it eventually did not attract sufficient funding and was also dissolved. The IOM has supported the development of HTA in various ways. In addition to developing the Coun- cil, a notable move was to form the Committee for Evaluating Medical Technologies in Clinical Use. The main output of the Committee was the development of a rather definitive book on the field of HTA, Assessing Medical Technologies (9). Since that time, HTA has not found a home in the U.S. Federal government, especially after OTA was abolished in 1995. However, several public and private sector developments that followed these events kept the field alive. The recent significant attention to comparative effectiveness in health care in the United States by the Obama administration indicates a much broader support for HTA in the United States (5).

Consensus development conferences, an important activity related to HTA, also developed first in the United States through the National Institutes of Health. These began in the United States in 1977, and such conferences have been held since that time at a rate of approximately 5 per year (10). The goal is to bring together various concerned partiesphysicians, researchers, economists, epidemiologists, consumers, ethicists, and so on-to seek consensus on the scientific basis of the safety, efficacy, and appropriate conditions for use of various healthcare technologies. A panel of experts listens to presentations by leading medical researchers addressing a specific set of questions. After 2 days of hearings, the panel is sequestered to write a consensus statement, which is read the next day and associated with a press conference. In the early years of HTA, consensus conferences were organized by public bodies in several countries, including Sweden, Denmark, Finland, France, the Netherlands, and the United Kingdom.

\section{INTERNATIONAL COLLABORATION}

\section{ISTAHC and HTAi}

Those working in HTA realized early on that HTA had to become an international field. By the mid to late 1970s, informal meetings were held with those who identified with such work. The OTA health program received a steady stream of international visitors, as did the Swedish Planning and Rationalization Institute of the Health Services (Spri). Exchanges between the two organizations became frequent, and in 1979, Spri sponsored the first international conference on HTA in Stockholm, involving individuals from several European countries and the United States (21).

The expansion in international contact prompted many of those working in HTA to attempt to form an international society or network of people interested in HTA. The first meeting was held in Copenhagen and attracted approximately sixty people from sixteen countries. The success of this meeting was unexpected by most, but was encouraging for the development of a society. ISTAHC was founded at the Copenhagen meeting with Seymour Perry as president. The new International Journal for Technology Assessment in Health Care was accepted a few years later as the official 
publication of ISTAHC. After 18 years, ISTAHC was liquidated for financial reasons in 2003. At its height ISTAHC included more than 1500 members. A new international society, HTAi, was formed in 2003, with Chris Henshall as president. HTAi presently has approximately 1000 individual members. It holds annual meetings and recognizes the journal as its official publication.

\section{INAHTA}

As national programs began to appear, the need for communication and cooperation at the agency level was recognized. Several international meetings led to the formation of INAHTA in 1993. INAHTA presently has forty-six members from twenty-four countries who work mainly on issues related to coordination of assessment, including carrying out joint assessments on occasion. These agencies are generally similar in the priorities they identify, the methods they use (mainly systematic review), and their relation to national and regional policy making. As increasingly better information has become available on the "value for money" of health technology, countries have become more involved in attempting to ensure that decisions are made with at least the input of HTA findings. An important example is the use of HTA as part of health insurance coverage decisions, which is a priority in countries such as the Netherlands, France, Switzerland, Spain, the United Kingdom, and some non-European countries, notably Brazil, Argentina, and Uruguay in Latin America and Taiwan in Asia.

\section{EuroScan}

Another membership organization for HTA is EuroScan, a voluntary organization composed of public HTA programs that are interested in early identification and assessment of health technology. EuroScan was founded in 1999 and presently has fifteen member organizations, all members of INAHTA. The English National Horizon Scanning Centre hosts the secretariat for EuroScan (see the EuroScan Web site for more details, including a detailed history).

\section{The Cochrane Collaboration}

The UK Cochrane Centre was established in 1992 to facilitate and coordinate systematic reviews of (mainly) randomized controlled trials. That Centre became the first Cochrane Centre in what would become the worldwide Cochrane Collaboration. The development and growth of the Cochrane Collaboration has been of great value to the field of HTA, for example, in terms of methodological improvements in searching and grading scientific studies, in access to systematic reviews and other important information, and in fostering a broader understanding of the need for evidence in clinical decision making and in health policy making. A history of the Collaboration is published in this issue, and more details on the events of its development are available at http://www.cochrane.org/docs/cchronol.htm.

\section{The European Commission}

The EU has played an increasingly significant role in HTA in its twenty-seven Member States, and in some developing countries (17). In the 1980s and 1990s, the EC, the executive arm of EU, funded several studies and meetings related to HTA. From 1994 to 1997, the EC funded the EUR-ASSESS project, composed of many of the fifteen then member states of EU, for the purpose of exploring possibilities to improve coordination of HTA in Europe (1;3). See study in this issue on HTA at the European level. That project was followed by the HTA-EUROPE project (4), which further aimed to improve coordination, but also carried out several recommendations, including development of country papers on HTA in the EU Member States. From 2000 to 2002, the EC funded the European Collaboration on Health Technology Assessment (ECHTA), which further examined the possibilities to improve coordination of HTA in Europe (12). Finally, in 2005, the EC funded a project named EUnetHTA to continue development of HTA activities among the present twenty-seven Member States in Europe (13).

These four projects have definitely improved coordination of HTA efforts. At least as important, however, is the fact that they have made HTA more visible. Today, most EU Member States have national and regional public programs for HTA, and most of the others are developing or considering such programs.

\section{The World Bank}

The World Bank has also been active in the field of HTA, sponsoring several consultations and conferences on the subject. More importantly it has included HTA in many of its recommendations to countries concerning their health services. The earliest known concentrated involvement in HTA by the Bank was in China during 1987 and 1988. Other countries that have received substantial support from the Bank to develop HTA include Malaysia, Poland, Romania, and Serbia. Although the Bank has promoted HTA in Russia and has helped develop a substantial body of experts, the government has not responded actively to these attempts. To date, no policy approach to HTA has been developed in Russia.

\section{The World Health Organization}

Health technology is global in the sense that results from health-related research, which may occur anywhere in the world, generally diffuse around the world fairly rapidly. For this reason, WHO was involved and interested in HTA from the outset. The Declaration of Alma Ata on Primary Health Care in 1978 (23) referred to "essential health care based on practical, scientifically sound methods and technologies ..." In 1985, the European Office of WHO published several targets for its member states, including one on HTA that stated "... all member states should have established a formal mechanism to systematically assess the appropriate use of health technologies and to verify that they respond to the 
national health program needs" (24). This target was met by a few countries, but was quietly removed from the next version of the WHO targets in 1991 (25).

The first meeting of the International Society for Technology Assessment in Health Care was held in 1985 with the cooperation of WHO Euro in its Copenhagen office. Unfortunately, WHO as a whole has never become a strong and consistent supporter of HTA. The European Office had a program related to HTA for several years, but actually worked more on quality assurance. Beginning in 2000, the newly elected Regional Director for EURO stated that development and use of evidence in healthcare decision making would be his priority, especially in the programs of the Regional Office itself. He revitalized the Evidence Unit of EURO and expanded its resources. He reconstituted the WHO European Advisory Committee for Health Research (EACHR) to focus on evidence. Among other things, that Committee developed a definition of the concept of "evidence" for policy making in public health (5). In addition, he supported a new program, the Health Evidence Network (HEN), to develop information on evidence of health interventions for the member states (www.euro.who.int/hen). However, in 2007 and 2008, WHO EURO became less active in promoting evidence-based activities.

WHO headquarters in Geneva became involved in HTA at least by the early 1990s. That office took an entirely different path. First, WHO depended on available evidence, particularly on efficacy, in some of its programs, notably essential drugs, diarrheal diseases, tuberculosis, and perinatal problems. However, many guidelines developed by WHO during the 1970s and onward were based more on expert committees' opinions than on systematic review of available scientific literature. This situation began to improve in the early years after 2000. During the 1990s, considerable interest in HTA emerged from certain parts of the office, including an Assistant Director General. Several interesting consultations were held, focusing on the development of national programs or networks of programs and individuals. However, no significant resources were committed to HTA or similar fields. Regional Offices were urged to become interested in HTA, but few responded. The Regional Office in New Delhi, India, however, did support one international workshop and course on HTA for its members in Bangkok in 1998. Under Gro Harlem Brundtland, Director General from 1998 to 2003, the use of best evidence was strongly supported. Although several individuals had strong interests in HTA, the thrust was more toward developing evidence on cost-effectiveness for member states to use. WHO-CHOICE (CHOosing Interventions that are Cost-Effective) began to assemble lists and regional databases on the costs, impact on population health, and cost-effectiveness of key health interventions. Examples can be found in the World Health report of 2002 (26) and also in a publication proposing a generalized method for cost-effectiveness analysis (6).
The key point among the authors of this study is that individual countries need the capacity to evaluate health technology based on their own needs. Only some individuals in what is now Health Technology and Facilities Planning in the Department for Health Systems Governance and Service Delivery have been involved in such activities. That program and its predecessors have provided funding for many individuals from developing countries to participate in ISTAHC meetings where they could meet potential colleagues and be introduced to the use of HTA in developed countries. However, in 2007, for the first time, the World Health Assembly of member states asked WHO to become more active in fields related to health technology, including assessment (27). WHO staff members have stated that this will lead to more involvement in HTA.

\section{PAHO}

The Pan American Health Organization (PAHO/AMRO, WHO for the Americas) began to promote HTA in the Americas as early as 1983. From the mid-1980s until the early 1990s, its Technology Development Unit supported important national and international meetings and consultations. In 1998, PAHO published a Regional Strategy for HTA. Some studies (assessments) were conducted and published, and documents from OTA were translated into Spanish and disseminated widely in the region. In the mid to late 1990s, health sector reform became an important movement in Latin America, and PAHO became even more active in promoting HTA. Collaboration of HTA agencies from Spain and Canada led to workshops on HTA and to training a critical mass of professionals linked to the decision-making process in Latin America and the Caribbean. Several countries, notably Mexico, Brazil, Argentina, Uruguay, and Chile, showed increasing interest in HTA. In 1997, MERCOSUR (Argentina, Brazil, Paraguay, and Uruguay economic initiative) organized a Technical Subcommittee on HTA. Since 2000, PAHO has redefined the approach to health technology through interaction with the countries in the region and has prioritized the strengthening of HTA programs as part of the new approach.

Other international organizations have played less prominent roles in HTA. The Organisation for Economic Co-operation and Development is one that has shown increased interest in HTA during the early 2000s. Although it has played a minor historical role in HTA, the organization did sponsor meetings on HTA in the early 1980s. The Rockefeller Foundation has also sponsored several HTA initiatives and meetings.

\section{FUTURE}

HTA has strong political support in many countries where agencies in the field have been established. This may be due mainly to the fact that resources for health care are limited. 
Hence, choices must be made, and rational choices need to be informed by evidence. The use of evidence, whether one calls it HTA, EBM, scientifically based health services, or something else, has become an essential element in modern health care at the policy, administrative, and clinical levels.

It is likely that HTAs of the future will move more closely toward the idea of comparative effectiveness (8). Many HTA agencies have been doing comparative effectiveness analyses since their inception, so the concept offers nothing new for them. Others, who are doing assessments by focusing on one technology at a time, will eventually recognize the advantages of reviewing and assessing all options concerning a specific technology, including health promotion and other forms of prevention. For example, to some extent colorectal cancer is one of the few preventable forms of cancer, but most published HTAs on the technology of screening for this condition do not include the option of prevention.

A major challenge for HTA in the future concerns impact - to bridge the gap between evidence and health policy and practice. This may require some type of mechanism to hold decision makers accountable for making use of evidence.

\section{POSTSCRIPT}

We feel a need to explain why we took this initiative to compile a history of HTA, particularly because we both find ourselves somewhat in the center of the story. We lived through this story and have both been active in HTA since it formally started over 30 years ago. We were both founding members of the International Society for HTA and served on its Board from 1985 to 2002.

David Banta was present at the creation of HTA, joining OTA in 1975 and being a major part of many of the events described in these studies. He worked as a researcher in OTA's health program, later became the coordinator of that program, and finally the Assistant Director of OTA. He has formally worked for the U.S. Congress, the U.S. Executive Branch, and was the deputy director of PAHO before moving to Europe to work for the Dutch government and serve as a staff member of WHO. He coordinated the first substantial European-wide efforts in HTA (EUR-ASSESS and HTAEurope). For almost a decade, he also served as a consultant to SBU in Sweden and participated in many international teaching and consulting activities in HTA.

Egon Jonsson was introduced to the need for evidence in medical care by Duncan Neuhauser and Archie Cochrane in 1973, and to more policy-oriented assessments by a group of researchers at the Center for Evaluation of Clinical Procedures at Harvard School of Public Health in 1974. He carried out several early assessments from the mid-1970s and established links with many of the staff of OTA, which was a main source of inspiration to establish HTA in Sweden. Egon
Jonsson was the founding director of SBU in 1987. In 1985, he became the first co-editor, together with Stanley Reiser, of this Journal (a position he still retains), founding member of INAHTA, and director of its secretariat from 1996 to 2003. He participated in the EUR-ASSESS project and headed the European Collaboration for Health Technology Assessment. Egon Jonsson also established the Health Evidence Network at WHO Euro and served as a health policy advisor to the Ministry of Health in Vietnam. He has participated in many international teaching and consulting activities in HTA and is currently the CEO for the Institute of Health Economics in Alberta, Canada, of which HTA is the major program (www.ihe.ca)

In closing this brief introduction, we would like to acknowledge the contributions of many friends and colleagues in our own work in HTA. We have often been given credit for events in the field that in many instances should have gone to others, at least partially. We value those individuals who have worked with us and contributed a great deal not only to our own work, but to our knowledge and perspectives. They are too numerous to mention by name.

The cost of printing and disseminating this special issue of the Journal has been covered by greatly appreciated grants from NICE in the United Kingdom, the Institute of Health Economics and CADHT in Canada, the Norwegian Knowledge Center, and the Swedish Council on Technology Assessment in Health Care, and by in-kind support from Cambridge University Press. Thank you all very much.

David Banta, MD, MPH (HD.Banta@orange.fr), Professor Emeritus, University of Maastricht, Maastricht, The Netherlands; 9 route de Bragelogne, 10210 Villiers-le-Bois, France

Egon Jonsson, PhD, Professor, University of Alberta, and University of Calgary, Editor-in-Chief, International Journal of Technology Assessment in Health Care, Executive Director \& CEO, Institute of Health Economics, \#1200, 10405 Jasper Avenue, Edmonton, Alberta T5J 3N4, Canada

\section{REFERENCES}

1. Banta D. Introduction to the EUR-ASSESS report. Int J Technol Assess Health Care. 1997;13:133-143.

2. Banta HD, Perry S. A history of the International Society for Technology Assessment in Health Care. Int J Technol Assess Health Care. 1997;13:430-453.

3. Banta HD. Coordinator. Report from the EUR-ASSESS Project. Int J Technol Assess Health Care. 1997;13:133-340.

4. Banta D, Oortwijn W. Introduction. Health technology assessment in the European Union. Int J Technol Assess Health Care. 2000;16:299-302.

5. Banta, D, European Advisory Committee on Health Research, World Health Organization Regional Office for Europe. Considerations in defining evidence for public health: The European Advisory Committee on Health Research World Health 
Organization Regional Office for Europe. Int J Technol Assess Health Care 2003;19:559-572.

6. Edejer T, Baltussen R, Adam T, et al. Making choices in health: WHO guide to cost-effectiveness analysis. Geneva: World Health Organization; 2003.

7. Hailey D, Menon D. A short history of INAHTA. International Network of Agencies for Health Technology Assessment. Int J Technol Assess Health Care. 1999;15:236-242

8. Hailey D, Jacobs P, Jonsson E. Comparative effectiveness $-a$ review of definitions. Edmonton $\mathrm{AB}$ : Institute of Health Economics; 2009. www.ihe.ca.

9. Institute of Medicine. Assessing medical technologies. Report of the Committee for Evaluating Medical Technologies in Clinical Use. Washington, DC: National Academy Press; 1985.

10. Institute of Medicine. Consensus development at the NIH: Improving the program. Washington, DC: National Academy Press; 1990.

11. Jonsson E. Development of health technology assessment in Europe. A personal perspective. Int J Technol Assess Health Care. 2002;18:171-183

12. Jonsson E, Banta HD, Henshall C, Sampietro-Colom L. Executive summary of the ECHTA/ECAHI project. Int J Technol Assess Health Care. 2002;18:213-217.

13. Kristensen FB. The EUnetHTA collaboration - way forward for HTA in Europe. Presented at the conference HTA's Future in Europe, Paris, 20 November 2008. http://www.eunethta.net/ upload/Paris_Conference/PPTs\%20Final/16_Kristensen_after noon_Paris_20_11_208.pdf.

14. Neuhauser D. Commentary. Int J Technol Assess Health Care. 1997;13:454-457.

15. Office of Technology Assessment. Development of medical technology, opportunities for assessment. Washington, DC: US Government Printing Office; 1976.
16. Office of Technology Assessment. Policy implications of the computed tomography (CT) scanner. Washington, DC: US Government Printing Office; 1978.

17. Office of Technology Assessment. The implications of costeffectiveness analysis of medical technology. Washington, DC: US Government Printing Office; 1980.

18. Office of Technology Assessment. Assessing the efficacy and safety of medical technologies. Washington, DC: US Government Printing Office; 1982.

19. Sisk JE. Commentary. Int J Technol Assess Health Care. 1997; 13:460-462.

20. Stocking B. Commentary. Int J Technol Assess Health Care. 1997; 13:458-459.

21. Spri. International Workshop on Evaluation of Medical Technology, Swedish Planning and Rationalisation Institute of the health services. Spri. 1979;3089:1.

22. Stocking B. News items. EEC: Medical technology assessment. Int J Technol Assess Health Care. 1987;3:623628.

23. World Health Organization. Primary Health Care. Report of the International Conference on Primary Health Care. AlmaAta, USSR, 6-12 September 1978. WHO, Geneva, 1978. http://whqlibdoc.who.int/publications/9241800011.pdf.

24. World Health Organization. Regional Office for Europe. Targets for health for all. Copenhagen: WHO; 1985.

25. World Health Organization. Health for all targets: The health policy for Europe. Updated edition. Copenhagen: WHO Regional Office for Europe; 1991 ISBN-13 9789289013116.

26. World Health Organization. World Health Report 2002. Geneva: WHO.

27. World Health Organization. Health technologies. Resolution of the 60th World Health Assembly. WA60-29. Geneva: WHO; May 2007. 